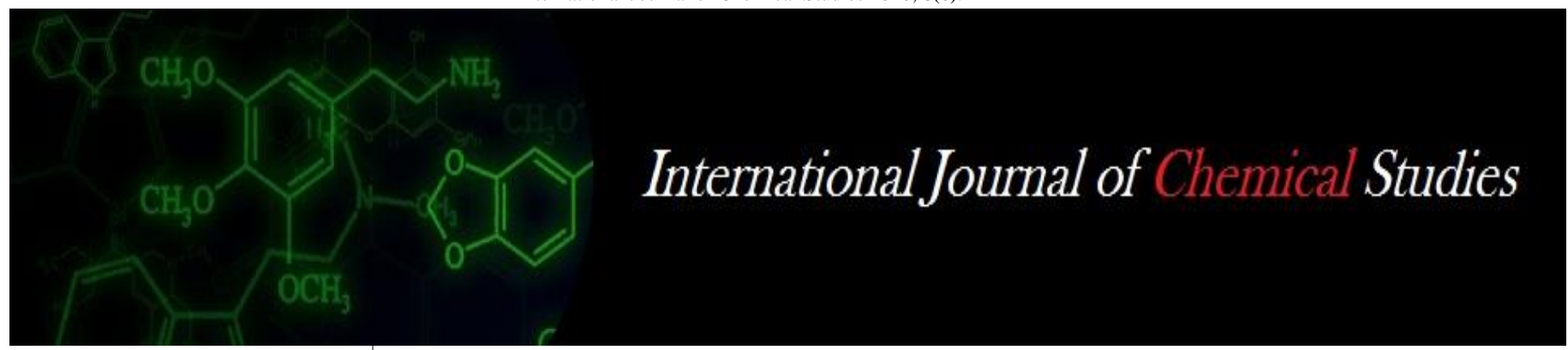

P-ISSN: 2349-8528

E-ISSN: 2321-4902

www.chemijournal.com

IJCS 2020; 8(6): 2211-2214

(C) 2020 IJCS

Received: 06-08-2020

Accepted: 15-09-2020

Khan Jabroot J

M.Sc. Scholar, School of

Agriculture, Lovely Professional

University, Phagwara, Punjab,

India

Dr. Deepika Sexena

M.Sc. Scholar, School of

Agriculture, Lovely Professional

University, Phagwara, Punjab,

India

Corresponding Author:

Khan Jabroot J

M.Sc. Scholar, School of

Agriculture, Lovely Professional

University, Phagwara, Punjab,

India

\section{Role of auxin in horticultural fruit crops}

\author{
Khan Jabroot J and Dr. Deepika Sexena
}

DOI: $\underline{\text { https://doi.org/10.22271/chemi.2020.v8.i6af.11101 }}$

\section{Abstract}

As we know auxins were the first class of plant hormones to be discovered that use to kill weeds, promote growth and fruit quality of particular plant.in this review paper I have compile the summary of Auxin as important hormone required to carry any essential function in plant viz., delaying, early maturation, help in rooting etc. I have categorized crop in accordance with role of auxin with tropical and temperate crops, which I hope could help scientist for further breeding programme, to acknowledge the role with its pros and cons.

In mango it mainly influence the girdling effect, fruit repining process, and in grape it helps in the maturation and quality maintenance of berries on the other hand in apple with the appropriate concentration it triggers the production of ethylene which eventually promotes ripening accompany it helps in the translocation of calcium which maintain the fruit quality.

In guava auxin is immensely used in the form IAA and IBA which operates as a rooting hormone in this crop to hasten the growth during layering on the other hand in pear and peach its application influence the growth of primary and secondary shoot.

Keywords: Auxin, phytohormones, PGR, IAA, IBA, NAA, tropical fruits, temperate fruits

\section{Introduction}

As we know that plants need light, water, oxygen and nutrition to grow and develop. But they also need some other factors that regulate the growth of plant and known as Plant Growth Regulators. Plant hormones are a group of naturally occurring, organic substances which influence physiological processes at low concentrations (Davis, 1995) ${ }^{[5]}$. On the bases of their use plant growth regulators may be divided into two categories i.e. Plant Growth Promoters (promote cell division, cell enlargement, flowering, fruiting and seed formation) and Plant Growth Inhibitors (chemicals inhibit growth and promote dormancy and abscission in plants).

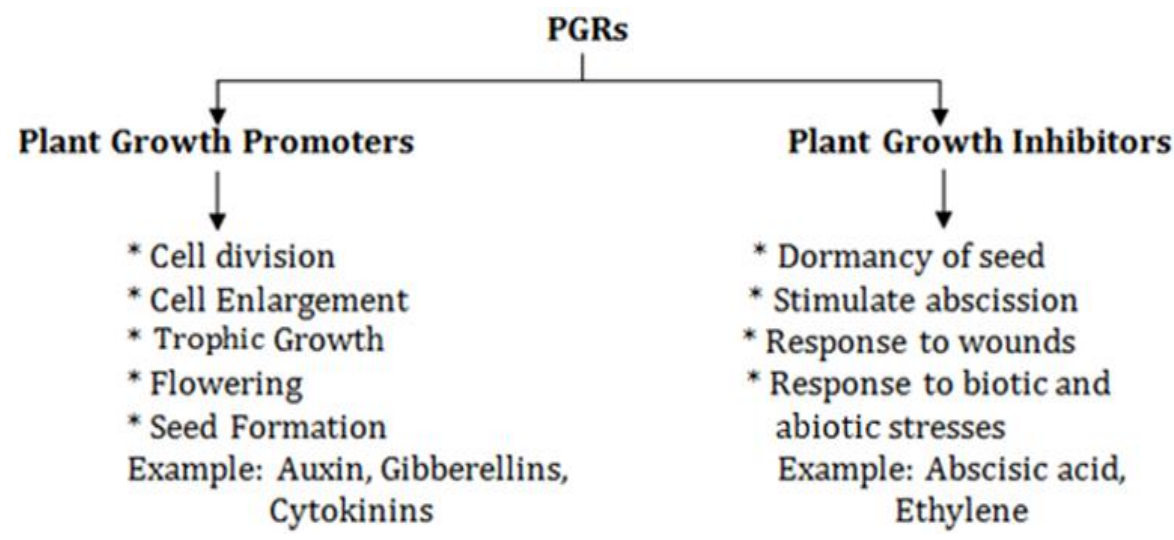

Auxin is the first class of plant hormone to be discovered. The word ' $\alpha v \xi \alpha v \omega$ ' in Greek, or 'to grow' in English, gives us 'auxin': the name of a small class of molecules with a powerful ability to induce growth responses in plants (Teale et al., 2006). Indole-3-acetic acid (IAA), the main auxin in higher plants, has profound effects on plant growth and development. Both plants and some plant pathogens can produce IAA to modulate plant growth (Zhao, 2010) ${ }^{[27]}$. Indole-3-acetic acid (IAA), is the natural form of auxin in plants and IBA (indole-3-butyric acid) that is synthetic form (Zazimalova et al., 2014) ${ }^{[26]}$. 


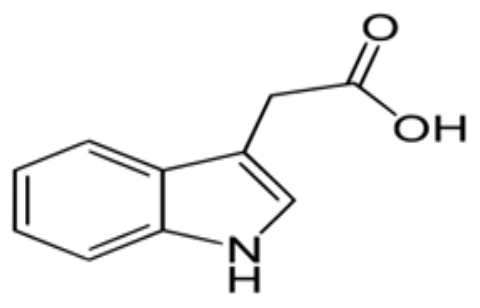

Indole-3-acetic acid (IAA)

Auxin promotes cell enlargement, inhibit growth of lateral buds and play important role in apical dominance. Indole-3acetic acid (IAA), the main natural auxin in plants and other is IBA (indole-3-butyric acid) that is synthetic form (Zazimalova et al., 2014) ${ }^{[26]}$.

Auxinsare considered to be factors in vegetative growth but under artificial conditions they can also cause fruit development without fertilization (Gustafson, 1939) ${ }^{[10]}$. IAA transport is cell to cell, mainly in the vascular cambium and the procambial strands, but probably also in epidermal cells. Transport to the root probably also involves the phloem (Davis, 1995) ${ }^{[5]}$.

It is a phytohormone that help in the fleshy fruit development, having been shown to be involved in the intial signal for fertilisation, fruit size through the control of cell division and cell expansion, and ripening related events (Devoghalare, 2012) ${ }^{[6]}$.

Therefore, to study the role of auxin in horticulture crops; I go through the related work done i.e. conducted by many researchers on different fruit crops to found out the effect of auxin on particular fruitcrop.

\section{Literature related to role of auxin in Fruits}

Literature related to the role of Auxin on tropical and temperate fruit crops are explained as follow.

1. Role of Auxin in Tropical fruit crops: - Mango, Guava, Banana, Grapes etc. are the important tropical fruit crops on which effect of auxin was reviewed.

2. Role of Auxin in Temperate fruit crops: - Apple, Pear, Peach etc. are the crops on which I reviewed the literature that is described below.

\section{Role of Auxin in Tropical fruit crops \\ - Auxin and Mango}

Parkash et al. (1983) reported that the rate of fruit growth in mango cv. Dashehari is marked to be low which eventually delayed the division of zygote and endosperm nuclei due to low production of auxin and they also observed that there is decrease in acidic and nonacidic auxin production from 42 days to maturity of the fruits hence lack of auxin is marked ultimately fruit growth is decreased.

Bhowmick et al. (2011) ${ }^{[1]}$ worked on fruit retention and fruit physico-chemical properties in mango cv. Himsagar andreported that auxin play crucial role in maintenance of ongoing physiological and biochemical activities, the also observed that it is totally dependent on auxin percentage present for the mobilization and translocation of nutrients.

Shivashankara et al. (2019) ${ }^{[21]}$ worked on mango to find out the relationship of various metabolites with flower sex ratio and fruit set using stem gridling technique. They reported that the rate auxin formation leads to maturation of fruit, the noticed in their experiment of 150 leaves that the girdling effect is influence profoundly when there is more availability of auxin which ultimately leads to generation of leaves, longest panicle.

\section{- Auxin and Banana}

Madhulata et al. (2006) ${ }^{[13]}$ studied effect of auxin I.e. indole butyric acid (IBA) and $\alpha$-naphthalene acetic acid (NAA) on invitro propagation of Banana. They reported that higher root induction rate was achieved at IBA and NAA combination (1:1) which leads to enlargement of call, root initiation, Suppression of lateral buds in initial stage in parts success to invitro propagation of Banana.

Buah et al. (2015) cultured the banana shoots in vitro on Murashige and Skoog medium supplemented with $2 \mu \mathrm{M} 1$ naphthylacetic acid (NAA), rooted earlier and also had more adventitious roots than those cultured on the medium without NAA. However, the adventitious roots formed on the medium without NAA showed more lateral branching.

Khalifah (1965) [12] observed that role of auxin in development of parthenocarpy banana fruit based on application NAA exogenously which leads to faster cell division by inversion of gene.

\section{- Auxin and Guava}

Shahzad et al. (2019) ${ }^{[20]}$ conducted an experiment with guava cv. (Chinese Gola) in which they took auxin that IBA with proportion of 1600ppm and 2000ppm and NAA @7000ppm and 10,000ppm. Along with five media soil, peat, mosses, sand, bagasse on 105 cuttings. They noticed that with nearly 1 month of application immense increase in root growth and root length.

Zamir et al. (2017) ${ }^{[24]}$ conducted an experiment to analyse the effect of deferent auxin on rooting in soft and semi-hard wood stem cuttings in guava. IAA was considered more effective then IBA, maximum increase in number of roots was recorded with application with IAA. Ultimately maximum of $28 \%$ survival rate was observed in soft-wood cutting when exposed to IAA @ $100 \mathrm{mg}$ per hundred-gram talcum powder combination.

Zamir et al. (2017) ${ }^{[25]}$ an experiment was conducted to generate protocol from seedling ex-plant of higher yield in guava cv. Safada. Where MS media was prepared constituting $1.5 \mathrm{mg}$ per-litter IAA and $1 \mathrm{mg}$ per litter NAA which are different auxin forms leads $76 \%$ improvement in rooting.

\section{- Auxins and grapes}

Bottcher et al. (2010) ${ }^{[2]}$ conducted an experiment on fleshy fruit of grape. Auxin i.e indole-3-acitic-acid (IAA) declines the initial ripening process which delays the ripening. They also observe that GH3 gene transcription encodes the IAA synthase which conjucates IAA to amino acids which in turn have positive correlation to combine application of ABA and sucrose to ethylene production which leads to ripening process. Davies et al. (1997) ${ }^{[4]}$ performend a treatment with grape berries with application of benzothiazole-2-oxyacetic acid (BTOA) i.e. auxin like compound which leads to delaying ripening after 2 weeks application they concluded that with the application of BTOA level of absisic acid (ABA) which influence ripening process.

Ziliotto et al. (2012) ${ }^{[28]}$ reported that in grape berry auxin acts as repressor of ripening inception with the application of auxin i.e. synthetic and non-synthetic delay ripening is observed in many cultivars manly in Merlot cause shift in the initiation of ripening.

\section{Role of Auxin in temperate Fruit crops \\ - Auxins and Apple}

Schaffer et al. (2012) [19] worked on apple and they suppressed the transgenic apples for the SEPALLATA1/2 
(SEP1/2) class of gene (MADS8/9) that showed severely reduced ripening were compared with untransformed control apples. They reported that the delay in ripening in apple is due to low auxin production they also said that MADS8/9 genes are responsible for rapid auxin production, they said lower auxin concentration is essential on onset of ripening to promote ethylene action also said that ethylene and auxin work antagonistically as ethylene will promote abscission and auxin will delay it.

Tomala et al. (1900) ${ }^{[22]}$ during the study on Red Delicious apples and they reported that rate of auxin generation in crops is positively correlated to $\mathrm{Ca}$ production and also observed that with the increase in auxin formation transport of $\mathrm{Ca}$ is influenced profoundly as $\mathrm{Ca}$ is very important for proper growth of seeds which indirectly dependent on auxin production.

Jankiewicz (1970) an experiment was conducted on apple, by applying auxin paste on wound of a young plant which leads to increase in crotch angle width, he also observed that the role of auxin is bi-directional, along with it auxin influence negative geotropism which demises the shoot curvature and auxin increases the mechanism pressure which imparts formation of new tissues with formation of cambium.

\section{- Auxin and Pear}

Frankel et al. (1973) ${ }^{[7]}$ conducted an experiment to analyse the effect of indole acetic acid on ripening of intact mature green pear cv. Barlett by vacuum infiltration technique and they concluded that IAA inhibits the chlorophyll broke down and softening along with IAA influence on ethylene evolution which eventually leads to ripening.

Frenkel (1975) ${ }^{[8]}$ evident an experiment in which ripening of pear cv. Barlett was also accelerate by treatment of indole acetic acid oxidation products, with overnight incubation of 0.1- and 1-mM IAA stimulate ethylene evolution by enzymatic degradation which promote fruit ripening.

\section{- Auxin and Peach}

Trainotti et al. (2017) conducted an experiment in peach fruits to analyse the role auxin during ripening the reported that auxin has ability to regulate the expression of deferent gene along with-it auxin had increased expression in mesocarp during ripening.

Park et al. (2017) ${ }^{[16]}$ treated peach shoots with aminoethoxy vinyl glycine (AVG) which is potent auxin bio-synthesis inhibitor leads to primary root elongation, lateral root development, root inhiation. On the other hand, longest exposer time of 14 days increases average rooting weight.

\section{- Auxins and other Fruit Plants}

Nagireddy (2013) ${ }^{[15]}$ under took an experiment to study the effect of various auxin i.e. IBA on rooting and survival of air layering in fig crop, by application of IBA @ 1000, 2000 and $3000 \mathrm{mg}$ improves the number of primary roots i.e. 39 and 58 at 30 and 45 days respectively and maximum fresh weight of shoot bio-mass was 34,35,43 at 45,60,75 days respectively. Qureshi et al. (2012) ${ }^{[18]}$ Studied the effect of plant growth regulators applications, at 40 and 70 days after pollination, on pre-harvest fruit drop and quality of 'Rothana' and 'Ghur' dates. They reported that fruit drop is mainly triggered by imbalance in level production of auxin and ethylene, they also observed that when embryo completes its growth, the development pf secondary endosperm starts and eventually leads to generation of auxin along this they stated that auxin and ethylene acts protagonistically which helps in inhibition of abscission layer.

Ghosh et al. (2009) ${ }^{[9]}$ worked on beneficial effects of plant growth regulators on yield and fruit quality in pomegranate cv. Ruby and they reported that auxin play crucial role in fruit weight upgradation and rate of increase in auxin production leads to increase in TSS level in fruits also very important in control of fruiting and flowering.

Meir et al. (2015) ${ }^{[14]}$ reviewed to summarize the mechanisms leading to auxin depletion in the abscission zone, evaluates the methods for estimation of the spatio-temporal auxin levels, demonstrates how auxin depletion occurs during natural, stress-induced, and artificially-induced organ abscission, and presents new evidence for early and late events resulting from auxin depletion which lead to organ abscission. They reported that by decreasing the rate of auxin production artificially imparts positive correlation to the sequence of events leading to organ abscission, the stress generated lowers down auxin formation which mediated by intermediate modulators, ethythene, ROS and carbohydrate starvation.

\section{Conclusion}

After review the literature based on the research done by different agricultural workers on various fruit crops, I concluded that auxin play the important role to induce the qualitative and quantitative factors of economically important fruit crops of tropical as well as temperate conditions. Impact of auxin on different fruit crops are as follow:

Mango - Decrease fruit growth due to low level of auxin, and the reported that auxin also play important role maturation of Fruits.

Grape - Delay ripening.

Guava- Increase root Growth.

Banana - Early rooting and higher root induction.

Apple - Delay abscission, Influence $\mathrm{Ca}$ transportation and leads to increase in crotch angle width.

Pear - Accelerate ripening and inhibits softening.

Peach -Leads to primary root elongation, lateral root development, root inhiation.

Pomegranate - Regulate yield and fruit quality.

Fig - Induce primary roots during layering.

Date palm - Induce fruit drop due to imbalance in level of auxin.

\section{References}

1. Bhowmick N, Banik BC. Influence of pre harvest foliar application at growth regulators and micro nutrients on mango cv. Himsagar. Indian Journal of Horticulture 2011;68:103-07.

2. Bottcher C, Keyzers RA, Boss PK, Davies C. Sequestration of auxin by the indole-3-acetic acid amide synthetase GH3-1 in grape berry (Vitis Vinifera L.) and the proposed role of auxin conjugation during ripening. Journal of Experimental Botany 2010;61:3615-625.

3. Buah JN, Kawamitsu Y, Murayama S. Nursery growth of banana (Musa ssp.) plantlets rooted on auxin-free and auxin-supplemented media. Plant Production Science 1998;1:207-10.

4. Davies C, Boss PK, Robinson SP. Treatment of grape berries, a non-climacteric fruit with synthetic auxin retards ripening and alters the expression of developmentally regulated genes. Plant Physiol 1997;115:1155-61. 
5. Davies PJ. Plant Hormones: Physiology, Biochemistry and Molecular Biology. Kluwer Academic Publishers, Dordrecht, the Netherlands; Norwell, MA, USA 1995, 115.

6. Devoghalare F, Doucen T, Guitton B, Kelling J, Payne W, Ling TJ et al. A genomics approach to understanding the role of auxin in apple (Malus x domestica) fruit size control. BMC Plant Biol 2012;12:1-15.

7. Frankel C, Dyck R. Auxin inhibition of ripening in Barlett Pears. Plant Physiol 1973;51:6-9.

8. Frankel C. Oxidative turnover of auxin in relation to the onset of ripening in Barlett Pear. Plant Physiol 1975;55:480-84

9. Ghosh SN, Bera B, Roy S, Kundu A. Effect of plant growth regulators in yield and fruit quality in pomegranate. Cv. Ruby. J Horti Sci 2009;4:158-60.

10. Gustafson FG. Auxin distribution in fruits and its significance in fruit development. American Journal of Botany 1939;26:189-94.

11. Jankiewicz SL. Mechanism of crotch angle formation in apple tree. Acta Agrobotanica 1920;23:171-81.

12. Khalifah RA. Gibberellin like substance from the developing banana fruit. Plant Physiol 1965;41:771-73.

13. Madhulata P, Kriubakaran SI, Sakthivel N. Effect of carbon source of auxin an in vitro propagation of banana. Biologia Plantaram 2006;50:782-84.

14. Meir S, Sundareson S, Riov J, Agarwal I, Hadas SP. Role of auxin depletion on abscission control: A review. Stewart Postharvest Review 2015;2:2-15.

15. Nagireddy PP. Effect of rooting media and IBA (Indole Butyric Acid) level om rooting and survival of air layering in fig (Ficus carica L) cv. Poona under middle Gujrat agro climatic condition. M.Sc. thesis. Anand agriculture university Anand, India 2013.

16. Park SH, Elhiti M, Wang H, Xu A, Brown P, Wang A. Adventitious root formation of invitro peach shoots is regulated by auxin and ethylene. Scientia Horticulturea 2017;226:250-260.

17. Prakash S, Ram S. Naturally occurring auxins and inhibitor and their role in fruit growth and drop of mango Dashehari. Scientia Horticulturae 1984;22:241-248.

18. Qurashi ADA, Awad MA, Elsayed MI. Preharvest fruit drop, bunch weight and fruit quality of Rothana and Ghana date palm cultivars as affected by some plant growth regulators. African Journal of Biotechnology 2012;81:14644-51.

19. Schoffer RJ, Ireland HS, Ross JJ, Ling TJ, David KM. Sepallata $1 / 2$ - suppressed mature apple have low ethelene high auxine and reduced transpiration ripening related genes. AOB Plants 2012;5:1-10.

20. Shahzad U, Kareem A, Altaf K, Zaman A, Ditta A, Yousafi Q et al. Effects of Auxin and Media Additives on the Clonal Propagation of Guava Cuttings (Psidium guajava L.) Var. Chinese Gola J Agri Sci Food 2019;10:1-5.

21. Shivashankar KS, Geetha GA, Roy TK. Influence of girdling on flower sex ratio, biochemical constituents, fruit set intensity in mango. Biologia Plantarum 2019;63:432-39.

22. Tomala K, Dilley DR. Some factors influence the Ca level in apple fruit. Acta Horti 1900;274:481-87.

23. Trainotti L, Tadiello A, Casadoro G. The involvement of auxin in the ripening of climatric fruits 2007.

24. Zamir R, Rab A, Sajid M, Ahmed I. Influence of zeatin, glutanin and auxins on roots and shoots organogenesis od guava $\mathrm{Cv}$ safeda seedling explants. Pure Appl Biol 2017;6:197-206.

25. Zamir R, Rab A, Sajid M, Khattak GSS, Khalil SA, Shah ST. Effect of different auxin on rooting of semihard and softwood cutting of guava cv. Safeda. The Nucleus 2017;54:46-51.

26. Zazimalova E, Petrasek J, Benkova E. Auxin and its role in plant development. Springer Wien Heidelberg New York Dordrecht London 2014, 21-38.

27. Zhao Y. Auxin biosynthesis and its role in plant development. Annual Review of Plant Pathology 2010;61:49-64.

28. Ziliotto F, Carso M, Rizzini FM, Rasori A, Botton A, Bonghi $C$. Grape berry ripening delay induced by a perversion NAA treatment is paralleled by a shift in the expression pattern of auxin and ethylene related genes. BMC Plant Biology 2012;12:2-15. 